\title{
Minimally invasive approach versus spinal fusion with Instrumentation
}

\author{
Kaptan $\mathbf{H}^{*}$ \\ Department of Neurosurgery, Dokuz Eylul University, Medical Faculty, Izmir, Turkey
}

\section{Introduction}

There are many articles in the literature about of spinal fusion with instrumentation. This approach "Instrumentation of lumbar stenosis and degenerative spondylolisthesis" is proposed taking into consideration the advantages and disadvantages.

We must also emphasize the importance of other methods; open laminectomies, unilateral approach bilateral decompression withwithout using tubular retractors and microsurgical bilateral approaches for decompression.

There are similar publications in the literature [1,2,3,5]. But, without using microsurgical approaches, this surgical strategy would be lacking.

I would like to comment on some points about others' approach. "minimally invasive approach" with open laminectomies may not lead to case of iatrogenic spinal instability. Thus, additional surgical intervention for instrumentation is not need. Decrease in operative blood loss, length of hospital stays ( 1 or 2 days) is generally observed in our patient. We did not use pre-postoperative narcotic but only analgesics. Operative time took 1-2 hours. There are not any patients with intraoperative CSF leakage.

Another discussion point is the question about whether spinal fusion with instrumentation would be necessary or not for lumbar stenosis because instrumentation is at a great cost. In addition, we could reach the same conclusion in other surgical methods (Minimal access" with open laminectomies or microsurgical decompression)

In my opinion; partial laminectomy is more applicable for the patients who are below 65 years. A more positive improvement was observed; total laminectomy is more suitable for patients above the age of $\mathbf{7 5}$ years. Nerve root decompression surgery is performed and in order to maintain a stable and balanced spine. In addition, our clinical experience shows that microsurgical unilateral approach for bilateral decompression of lumbar is better than open laminectomies. This method seemed advantageous in minimizing the procedure and accompanying morbidity in this elderly population $[2,3,4]$.

\section{Conclusion}

As a conclusion, we always prefer as minimally invasive approach with open laminectomies or microsurgical decompression.

\section{References}

1. Musluman AM, Cansever T, Yılmaz A, Çavuşoğlu H, Yuce I, et al. (2012) Midterm outcome after a microsurgical unilateral approach for bilateral decompression of lumbar degenerative spondylolisthesis. J Neurosurg Spine 16: 68-76.

2. Kaptan H, Kasımcan O, Çakıroglu K, İlhan MN, Kılıç C, et al. (2007): Lumbar spinal Stenosis in Eldery Patients. Annals of The New York Academy of Sciences 1100: 173178

3. Kaptan H, Ilhan M, Çakıroglu K, Kasımcan O, Kılıç C, et al. (2010) The Analysis of the Factors Affecting Lumbar Spinal Stenosis in Adult Patients. Irish Journal of Medical Science. Ir J Med Sci 179: 365-368

4. Morgalla MH, Noak N, Merkle M, Tatagiba MS (2011) Lumbar spinal stenosis in elderly patients: is a unilateral microsurgical approach sufficient for decompression? $J$ Neurosurg Spine 14: 305-312.

5. Fourney DR, Dettori JR, Norvell DC, Dekutoski MB (2010) Does minimal access tubular assisted spine surgery increase or decrease complications in spinal decompression or fusion? Spine (Phila Pa 1976) 35: S57-65.
Copyright: (C)2017 Kaptan H. This is an open-access article distributed under the terms of the Creative Commons Attribution License, which permits unrestricted use, distribution, and reproduction in any medium, provided the original author and source are credited.
Correspondence to: Hulagu kaptan, MD, Associate Professor in Neurosurgery, Dokuz Eylul University Medical Faculty, Izmir, Turkey, E-mail: hulagukaptan@ yahoo.com

Received: October 11, 2017; Accepted: November 01, 2017; Published: November 03, 2017 